\section{Medical students' perceptions on euthanasia and physician-assisted suicide: Are they fully informed?}

To the Editor: In the June 2018 edition of SAMJ, Jacobs and Hendricks ${ }^{[1]}$ report on a survey of the perspectives on euthanasia and physician-assisted suicide (E-PAS) of 277 medical students at a single institution. The authors report that $52.7 \%$ of the respondents were in favour of legalising E-PAS in South Africa (SA) and that $47.7 \%$ believed that doctors assisting patients to this end should not be prosecuted for their involvement. They conclude that the responses demonstrate increased support for the legalisation of life-ending interventions compared with a 2011 survey of SA doctors, where 34\% supported the legalisation of voluntary active euthanasia. They also suggest that the students surveyed showed sound ethical judgement in selecting patients for life-ending interventions and in safeguarding the decision-making process, which was likely to translate into the ethical practice of E-PAS in their professional careers.

It is our conviction that the bioethical landscape of E-PAS cannot be complete without a thorough understanding of the practice and ethics of palliative care (PC). SA is a democratic country, but it is an undisputed fact that lack of resources impedes the delivery of healthcare services to the $>80 \%$ of South Africans using the public healthcare system. In a country where access to dialysis, intensive care beds, basic cancer treatment and antiretrovirals is not guaranteed, the question of E-PAS becomes all the more complex. It is only through fully understanding the benefits and limitations of medical interventions, and particularly PC interventions, that informed opinions on E-PAS can be reached.

We would like to argue that the opinions of these medical students with regard to E-PAS may not be fully informed. Although bioethics forms part of most SA undergraduate medical curricula, dedicated teaching and assessment of PC does not. Even though they would also have been exposed to patients experiencing suffering towards the end of life, this exposure would have been limited in terms of time, continuity and responsibility. Furthermore, not all teaching hospitals have fully integrated PC services, i.e. students' experience of comprehensive PC would have been limited. Currently, the multidisciplinary support services, including social, counselling and home-care services in hospitals and communities, are also significantly overburdened and underfunded.

The request for a life-ending intervention is often an expression of a person's existential suffering and mostly stems from fear of the unknown and loss of independence and control. ${ }^{[2]}$ Importantly, a person's experience of their suffering can change over time, as is evidenced by careful reading of the Stransham-Ford appeal judgment. ${ }^{[3]}$

We as PC practitioners believe that such a request for a life-ending intervention should compel the patient-centred health practitioner to apply the principles of PC as set out by the World Health
Organization ${ }^{[4]}$ and to use skilful conversations to explore patients perceptions of their suffering, their burden to others, their likely disease trajectory and personal goals of care. Good PC enhances patient autonomy and decision-making capacity by improving symptom control and empowering patients to participate in their care. We trust that through the planned implementation of the Department of Health's National Policy Framework and Strategy for Palliative Care, in line with the World Health Assembly resolution (67.19) on the strengthening of PC as a component of comprehensive care throughout the life course ${ }^{[5]}$ all SA patients requiring PC will soon have access to it throughout the continuum of care.

We would like to commend the authors ${ }^{[1]}$ for contributing to the ongoing discussion of a sensitive and often-debated bioethical issue locally and abroad. We would be very interested to see such a survey repeated to empirically evaluate whether the implementation of structured PC teaching in medical undergraduate curricula might effect a change in outcome.

\section{Henriette Burger}

Division of Radiation Oncology, Department of Medical Imaging and Clinical Oncology, Faculty of Medicine and Health Sciences, Stellenbosch University and Tygerberg Hospital, Cape Town, South Africa henrietteburger@sun.ac.za

\section{Liz Gwyther, René Krause}

Division of Family Medicine, School of Public Health and Family Medicine, Faculty of Health Sciences, University of Cape Town, South Africa

\section{Mpho Ratshikana-Moloko}

Centre of Excellence for Palliative Care, School of Health Sciences, Faculty of Health Sciences, University of the Witwatersrand and Chris Hani Baragwanath Hospital, Johannesburg, South Africa

\section{Derek Hellenberg}

Division of Family Medicine, School of Public Health and Family Medicine, Faculty of Health Sciences, University of Cape Town, South Africa

\footnotetext{
1. Jacobs RK, Hendricks M. Medical students' perspectives on euthanasia and physician-assisted suicid and their views on legalising these practices in South Africa. S Afr Med J 2018;108(6):484-489. https:// doi.org/10.7196/SAMJ.2018.v108i6.13089

2. De Lima L, Woodruff R, Pettus K, et al. International Association for Hospice and Palliative Care position statement: Euthanasia and physician-assisted suicide. J Pall Med 2017;20(1):8-14. https://doi. org $/ 10.1089 / \mathrm{jpm} .2016 .0290$

3. Minister of Justice and Correctional Services v Estate Stransham-Ford (531/2015) 2016 ZASCA 197 (6 December 2016)

World Health Organization. National Cancer Control Programs: Policies and Managerial Guidelines. 2nd ed. Geneva: WHO, 2002

5. World Health Assembly. http://apps.who.int/medicinedocs/en/d//s21454ar/ (accessed 3 August 2018)
}

S Afr Med J 2018;108(9):705. DOI:10.7196/SAMJ.2018.v108i9.13528 